\title{
PROFILING CUSTOMER TYPES IN LUXURY RETAIL SETTING
}

\author{
Tisovski, $M$.
}

The type of customer who buys luxury is continuing to evolve. This research investigates the value and service-dominant theory effects on the value co-creation process between a service provider and service consumer within the luxury retail environment. The goal of the paper is two-fold: first, to offer a new view on value co-creation and second, to suggest potential in-store target segments based on experiential drivers in order to improve value sharing within luxury stores for diverse luxury shoppers. In other words, the author noticed a gap between the existing writing and practice - customer involvement has become interactive, and not neglected. The paper, thus, introduces four groups of customers: Experts, Popular, Exclusive and Aspirational. The methodology used combines analyses of four value creation denominators within the luxury setting: actor's role, aesthetics, networks and luxury brand with findings from secondary research to integrate into the existing writing in this field.

The managerial implications mainly target brand managers of luxury and premium brands with the objective to offer insights on how to address, with higher precision, the types of clients visiting and shopping for luxury products.

JEL classification: M37

Keywords: luxury; value co-creation; service-dominant (S-D)

\section{Introduction}

Reaching the luxury customer is no longer the domain of the exclusive salon - the global luxury market boom and the phenomenal growth of luxury stores now view the retail sector as key to driving brand profitability. In this light, a consumption space can be viewed as communicational, experiential, sensorial brand enhancement and search for the meaning and value co-creation. In addition, when perceiving luxury brands, the value of a product is a mental estimation the consumer makes of it. Understanding the value dimension of luxury and experiential marketing practices is a good way for further development of marketing luxury brands. To co-create the value, marketers influence consumers to derive subjective intangible benefits from these goods beyond their functional utility, while additional motivations to purchase them include their higher levels of quality and authenticity. Thus, today we see more relevance of semiotics in retail and sensorial marketing strategies developed to produce dream worlds around luxury brands.

Categories developed in this work are based on soft communication factors such as aesthetics, emotions and symbolic aspects of a shopping space. There are also other aspects such as: superior service orientation, location, architecture, design colors and brand elements, product selection and availability, curated merchandize, aesthetics appeal, alignment with line communication and press coverage, and staff.

Knowing how to recognize, categorize and communicate is of importance to luxury marketers. Such learning could be adapted to other markets. Therefore, this research contributes to the understanding of interpretation of luxury and perception of value that affects the purchasing behavior of wealthy consumers.

\section{Value Co-Creation and Service-Dominant Logic}

The value co-creation model is based on the work of researchers like Gronroos (2008) and Payne et al. (2008) but shows an adaptation of the conceptual framework of value co-creation that was offered by Andreu et al. (2010). However, the point of difference is that the former authors addressed value co-creation through two separate perspectives: the process perspective offered by Payne et al. (2008) and the actor's perspective offered by Gronroos (2008). The latter, integrated the two previous frameworks. 
This paper supports the logic of both approaches, but examines the actor's roles perspective. Therefore, the model only addresses the Gronroos (2008) approach, which highlights the role of the actors. From this, it follows that the user determines that a value and service are defined through customer-oriented benefits with relational co-creation. Differently said, retailers need to coordinate supply relationships and competences to meet customers' needs and also build networks. Customers, reciprocally apply resources, knowledge, behavior and feelings to transform employee-level skills into experience. The way the company manages internal operational resources and develops superior competences creates the value that can provide differentiation on the market. Thus, it can provide more competitive ways to reach customers better than other companies.

Service-dominant (S-D) logic is a fundamental basis for exchange. S-D logic sees service as a unifier through which specialized competences are applied for the "benefit of another entity" (Andreu et al., 2010). S-D logic insists on a process of value co-creation where the customer has a role of co-creator and where the role of the company is to offer its best resources for value creation. So, S-D logic rests on integration, as the roles of customers and company are joint. An illustration of the experience-based value co-creating process is depicted in the model below (Figure 1.).
Since customers have changed and customer involvement has become interactive and not neglected, the evidence from literature and previous research has led to an adaptation of the existing model. Thus, the paper suggest the introduction of the dimension of 'experience perspective' implemented through networks, aesthetics and the luxury retail brand as the newer approaches underline the customer as value co-creator where "the brand becomes the experience" (Prahalad and Ramaswamy, 2004). Even though the customer is in focus, retailers and consumers jointly integrate resources and competences, expectations and experience provision into service provision. In this regard through aesthetics, networks and a brand-as-experience, the role of supplier is enriched by knowledge and understanding how to support co-creation activities of the customer and to address brands and branding in terms of more personalized experiences.

\section{Aesthetics Perspective of Service Dominant Logic}

Aesthetics in the luxury settings is a strong differentiator. Aesthetics is seen as giving the client something more than just a product and putting the product in the spotlight. Through aesthetics, a retailer can inform, involve and educate. This perspective influences the division of stores and its communicational and service

Figure 1: Conceptual Experience-Based Value Co-Creation Model

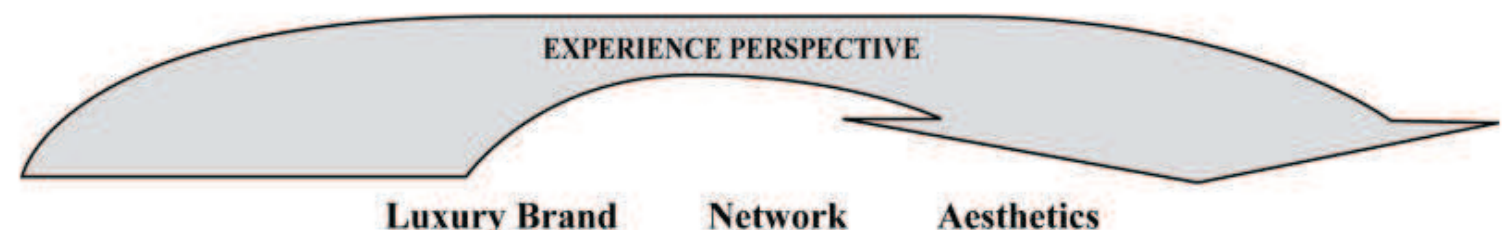

SUPPLIER

SUPPLIER-CUSTOMER

CUSTOMER
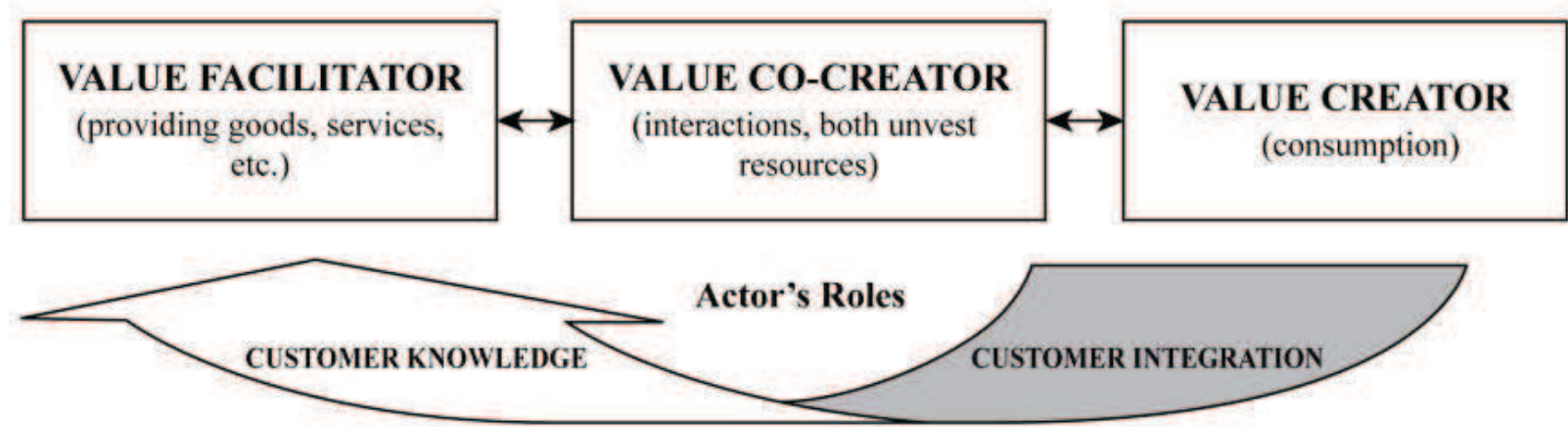

Source: Based on value co-creation Actor's Roles, Gronroos (2008) - adapted by the author 
logic. Creating an aesthetic appeal is a process that needs to attract customers, both as a shopper and an observer, so that co-creation keeps on evolving while delivering multiple benefits; a window display invites us in but also inspires us with regard to what to wear, eat or listen to, how to combine, etc. and shows the themes of the underlying campaign as well as core of the brand. In this view, aesthetic counts to add value and co-create value as customers are more attached to the perceived benefits of the product.

To co-create the value in the S-D logic, aesthetic departs from its "esoteric" nature (Simonson, 1999) in customers' lives and provides opportunities for companies to stress on appeal through various sensory touch points to enhance the product's features. It goes from Becoming to Belonging. The crucial element to make this happen is the placement of familiar objects of appreciation in unexpected and changing settings. Placing the aesthetic in the S-D context argues that taking an interest in aesthetic value of the object or space triggers the associations with symbols and plays with some attractive quality. The proper way to co-create value with and through aesthetics is to use consistent and simple, yet planned and unconventional implementation. The accent is on creating the entire look and supremacy and a feeling so strong that the message is clearly delivered to the right target. In turn, these dimensions will give better segmentation of customers if they are in for conspicuous, aesthetic or experiential possessions thus impacting the store environment and service. Preferably, managers could thus gather the knowledge if the customer is exclusive - with a deep visionary taste, or popular - only interested in possessions and glamour buzz, or, if a customer is a connoisseur - in search of enduring refined quality, or more aspirational and into 'buying the status.'

\section{Network Perspective of Service-Dominant Logic}

In the luxury market, interactions are exclusive in nature. The network perspective draws out the talent and creativity and tailored made solutions.

The position of the network within S-D logic for luxury brands and stores is valuable because luxury brand owners are given the opportunity for specific knowledge gathering. On one side, there is an option to co-create value with other brands in the network or community through interactions with customers, brand staff and competition. This approach is offering the visibility and involvement in a dialogue with network members. In turn, it helps in staying present and in constant communication while being able to detect all "wanted" elements necessary for meeting customers' desires. Having the place to encounter and be seen, and a place to listen and learn, can provide gathering and multiple interactions offering the exchange of intangible value of prestige. In terms of co-creating a service, the relationship with network members opens up the avenues of knowledge and information that serve later as cues to develop the 'differentiated, desired and difficult to copy' aspect (Tynon et al., 2010) of a luxury experience. Such experience is created through a variety of interactions with: networks of high status individuals, experts such as curators of museums or designers, symbols of popular culture, renowned musicians, a photographer, graphic artist, editors and journals (Tynon at al, 2010).

Engagement and care is found in initiatives like private dinners, parties for selected and influential individuals, bespoke service and exclusive club memberships. Being part of such an experience with the customer is creating much value. This gives suppliers a broader view of the context of their project and a more creative solution set to deliver exclusivity, recognition, and prestige. The network contexts interplay with consumers selves by integrating those sets of values that he/she identifies with, loves, desires and respects.

\section{Luxury Brand Perspective of the Service- Dominant Logic}

The nature of brand in the context of service-logic is motivating the retailers to think about creating emotional links through facilitating interaction with customers and brands in lavish settings where it has proven to be possible to enhance the customers' attention and participation in the value creation process by offering involvement. Aaker et al. 2004 referred to this issue in his conceptual model as 'customer - brand relationship' where brand personality plays the role in strengthening relations. Relational and experiential value is delivered through brand personality and a retailer should use its brands to create the experience and sensory atmosphere so that brand experiences appeal to the human mind and senses and guide consumption experience toward being memorable. By all means these interactions are highly subjective and therefore hard to evaluate.

Since in contemporary consumption consumers seek novelty, imagery and entertainment, multisensory brand experiences co-create value for luxury settings and customers by providing consumption aligned with "fantasies, fun and feelings" (Hoolbrook and Hirschmann, 1982). Unlike with networks, within the luxury setting, they provide longer exposure to their universe only where they can apply various technological 
devices and observation methods. Value is co-created not only through sensations but they enhance the products and environment's ability to link individuals with unique brand-experience. Also, there is the risk of triggering negative sensations.

\section{Marketing Implications}

Aesthetics, luxury brands and networks are dimensions that take time to develop. They give a touch intended to boost the consumption that goes beyond reason. The more they move toward experiences, the more refined the approach. This is an intimate level of communication as it advocates emotions, one's desires, fantasies and passion. Also, it is multi-faceted combining art, culture, and music. Owning such a brand isn't as relevant as experiencing it. In addition, to maintain the flair and connections with a 'special world' it still has to be able to compete on the nuances to preserve the cult. In luxury, the important thing is to stay true to the source of expertise of your brand. It is what is keeping the meaning and identity.

The experience perspective is the function of development of all three dimensions. That is why a luxury setting is important as it emphasizes the value of the product and service and it can also use the stores to appeal to different segments. It offers the way to segment in-store and store settings, offer and accommodate different expectations.

This being said, this work introduces experience and value-based segmentation. The idea is to depict in-store directions based on recognized characteristics for each category of customer. As experiential appreciation matures with time, moving between 'Becoming' and 'Belonging' a customer can experience the environments based on perceived value ranging between 'Exclusive Excitement' and 'Symbolic Desire' management.

Thus, this research offers conceptual and generic store setting segmentation such as: Exclusive, Aspirational, Expert, and Popular (Figure 2). These are defined through service level, staff behavior, displayed offer, wow effects, individualization and innovation.

Exclusive: This segment resides in the quadrant depicting Belonging and Exclusive Excitement. Here, a luxury reputation is 'earned and learned' (Berthon and Layland, 2009, pp. 45-66). It represents the stores that set standards and educate. Value is co-created thanks to exclusive high net worth individuals that are in search for the special and unique aesthetical appeal and reliant on networks. The demand should be limited to rare, visionary products in unusual settings that will provide the excitement only to a selected few.

Figure 2: In-Store Segmentation

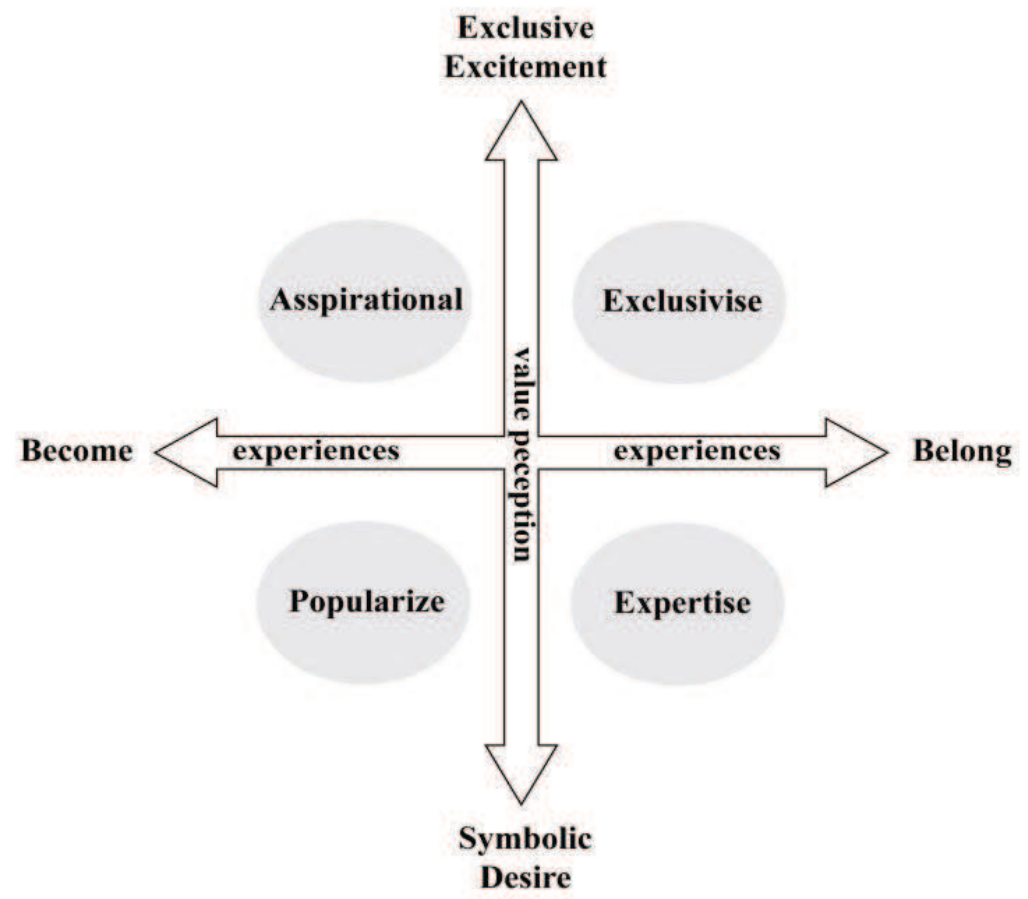

Source: Author, 2012 
Service should offer an international experience and merchandize displays should give the feel of sophisticated but niche consumption. In order to reach them, specialized magazines, limited-access Internet sites, word of mouth, and event marketing strategies with high marketing exclusivity have to be implemented. Their distinguishing characteristics are their regular connections to exclusive marketing environments and extensive contacts to various networks of other rich people. This level clearly demarcates ,,another world“. Here the network aspect of value co-creation is dominant. Moreover, research on high net worth individuals showed that "many customers of this group are often disappointed by the service level provided to them by luxury companies, and would be willing to spend more in many categories, could they find offerings that are more tailored to their individual needs" (Fluch and Maximilians, 2008 p. 10-13). Therefore, the essential point is to create an environment that is limited, where higher customer value is recognized and uniquely personalized.

This means, using techniques such as club marketing, where rich people are gathered by common interests, in combination with added value conferred by privileges, concierge services, and special experiences that are neither mundane nor easily accessible.

This creates a setting where reaching distant networks of luxury consumers who are not yet customers of the luxury company is made easy. They are more intimate and don't want their lifestyle to be copied but rather enriched with novelty that will than create a sensation worth paying for. Here infusion of art in the space or a visit by an artist, niche writer, musician, sculptor is welcomed. There also has to be some higher goal to support, an underlying idea that will create word of mouth within the limited club as they can support and influence it. An example could be a humanitarian initiative, specialized watch collection discussed by a creator, or yacht architect demonstrating the latest features.

Aspirational: The aspiration driven customer is to be found in the quadrant between Become and Exclusive Excitement. They desire to Become and imitate the lifestyle of an icon. Usually, they are interested in products that exemplify their taste and personality inspired by an idol. In order to distinguish these offers from normal products, it is essential to clearly mark them as being special, for example by creating luxury spaces within department stores in which the upscale consumer can feel more comfortable by making the offers and approaches more personally relevant to the respective customer segments, and by appealing to their heightened sophistication that marks them as different imitating social codes of the upper class. Use icons in the space. The obtained luxury product or service itself, considered appropriate to one's own lifestyle or level of social success, gives the consumer pleasure by transferring that message to others.

Popular: The $3^{\text {rd }}$ quadrant of Become and Symbolic Desire refers to conspicuous consumption, and the "mass luxury consumer" in search of 'bling' to show off. Inspiration comes from current trends found in magazines and on celebrities. Here, the social aspect is important; what the others will say? Therefore, buying something trendy provides associations that the social environment will recognize. They are neither intimate nor willing to be. The space has to offer a story that can be retold. Service doesn't have to be personalized, but immersing. The space, merchandizing and windows should draw attention and be in the media. They should position it as a "must see place" with a "must buy' items. Also the space should be dynamic and changing fast. Luxury brands that are present in these settings use them to generated profit for mass collections or affordable collections that won't be offered to the Expertize group. Price and location are important. Characteristic is being accessible in price and physical location. The influence of style magazines and celebrities is strong.

Expert: The last quadrant is Belong and Symbolic Desire. Consumption here is toward heritage and class. These consumers create value through exchange of expertise and history. These are collectors of symbols with refined taste. They don't change so easily and like relying on the true value of the product. In service they want devotion, knowledge and discussion.

Space should be calm and offer information. Products should be selected or obtainable from specialized sources. Merchandize should be displayed like gallery items. For this group, value in use is more relevant than value in exchange. Once they purchase the product or service, they want to be sure it is worth it. Post-purchase service is also important here especially in the form of event invitations for connoisseurs.

\section{Conclusion}

The value co-creation for luxury settings is still heavily resting on S-D logic while finding strategic marketing ways to move toward experience-based logic. The model presented depicted the roles of supplier, i.e. retailers and customers, and tries to describe the flow of value co-creation amongst them in experience driven society. Further, it departs from the integral view given by Andreu, Mele et al., 2010 who joined processes and actors' role and focuses only on actors' role, instead. 
These roles are enhanced in the model by dimensions such as aesthetics, luxury brand and networks. Managers could use the logic in order to analyze the luxury potential of a category focusing on different drivers emerging from these dimensions such as: individualization, detail focus, specialized items, strict rules of aesthetics, top in class performance, and experience.

Given the evolution of a luxury customer from passive to active, managers of luxury brands have to incorporate experience logic, multisensory focus of customer treatment and service providers who engage in dialogue, online interactivity and digital technology. The model and segmentation suggested are conceptual in nature with the goal to discuss a gap in current practices and move forward the thinking on solutions to effectively enhance communication between luxury brands and potential consumers.

The key contribution of the paper is the new, experiential model designed to show an integrated approach on how value co-creation is related to each of the four experiential perspectives by introducing networks, aesthetics and luxury brand. Though the concept is derived from theory only, without being tested, it offers the potential to be verified in further research and generate field data.

\section{References}

Aaker, J., Fournier, S., Brasel, S. A. (2004). When Good Brands Do Bad. Journal of Consumer Research, 31 (1): 1-16.

Andreu, L., Sanchez, I., Mele, C. (2010). Value co-creation among retailers and consumers: New insights into furniture market. Journal of Retailing and Consumer Services, 17: 241-250.
Berthon, P., Leyland, P., et al. (2009). Aesthetics and Ephemerality: Observing and Preserving the Luxury Brand. California Management Review, 52 (1): 45-66.

Fluch, H., Maximilians, L. (2010). The "New Rich" and the Premium Segment in Japan: Marketing Strategies in the Face of Changing Consumer Behavior. Marketing for the New Rich, 10-13.

Groonroos, C. (2008). Service logic revisited: who creates value? And who co-creates? European Business Review, 20 (4): 298-314.

Holbrook, M. B., Hirschman, E. C. (1982). The Experiential Aspects of Consumption: Consumer Fantasies, Feelings, and Fun. Journal of Consumer Research, 9: 132-40.

Payne, A. F., Storbacka, K., Frow, P. (2008). Managing the co-creation of value. Journal of the Academy of Marketing Science, 36 (1): 83-96.

Prahalad, C. K., Ramaswamy, V. (2004). Co-Creation Experiences: The Next Practice In Value Creation. Journal of Interactive Marketing, 18 (3).

Tynan, C., Chhuon, C., et al. (2010). Co-creating value for luxury brands. Journal of Business Research, 63: 1156-1163.

Wiedmann, et al. (2007). Measuring Luxury Value Perception: A Cross - Cultural Framework, Academy of Marketing Science Review, 7.

\section{Author}

Ing. Marija Tisovski, Ph.D. Assistant Professor - Marketing Communications Department of International Trade, Faculty of International Relations nám. Winstona Churchilla 4, 13000 Prague, Czech Republic marija.tisovski@vse.cz 